\title{
MOISTURE ABSORPTION AND DIMENSIONAL STABILITY OF POPLAR WOOD IMPREGNATED WITH SUCROSE AND SODIUM CHLORIDE
}

Pařil Petr ${ }^{1, \$}$, Dejmal Alešs

\begin{abstract}
This paper deals with the effect of vacuum-pressure impregnation of Poplar wood (Populus alba) by aqueous solutions of sucrose and sodium chloride on its physical properties. Groups of samples with different concentrations of substances in the aqueous solution were compared within each other and also with a reference (non-impregnated) group. The specimens from all groups were tested for density, moisture absorption and dimensional stability. The obtained data were statistically analysed and compared each other. The most satisfying final properties were achieved in impregnation of sucrose with concentration of $6,25 \mathrm{~g} / 100 \mathrm{ml} \mathrm{H}_{2} \mathrm{O}$. The retention was $31 \mathrm{~kg} \mathrm{~m}^{-3}$ (WPG around $8 \%$ ). The values of ASE (anti-swelling efficiency) reached to $36 \%$ and MEE (moisture exclusion efficiency) was reduced by $33 \%$.
\end{abstract}

Keywords: Wood modification, sodium chloride, sucrose, vacuum-pressure impregnation, swelling, equilibrium moisture content.

\section{INTRODUCTION}

Today, wood is a very frequently used material. In comparison to other competitive materials it offers many advantages including the following ones: wood is a renewable material, given its weight it provides a very high strength and elasticity, it has good thermal insulating properties, it can be easily shaped, it is ecologically recyclable and, last but not least, it has its indisputable aesthetic qualities (Gryc et al. 2007, Baar and Gryc 2012). But there are also some disadvantages. One of them, hygroscopicity, which induces dimension changes, was examined in this study.

Wood impregnation by natural substances with the aim of modifying its properties has been well known for decades and even centuries. At the break of the industrial revolution mainly synthetic-based substances were preferred - these were artificially produced with frequent negative side effects both on human beings and on the environment. The current trend in many fields of human activity is to return to original harmony with nature and a harmless use of natural renewable resources (Hill 2006). Products made from materials which were modified by natural means can be recycled environmentally friendly. Advantages of the new generation of "eco-modified" products are: first, that the material comes from renewable resources (e.g. wood); and second, that also the impregnation substance is from such resources (e.g. substances obtained from plant processing or, ideally, as waste and by-products). Third, their energy efficiency should be low. One of such technologies is e.g. modification of wood impregnation by sugars (Vigué 2006).

Wood modification by pure sucrose is mainly used for conservation of wooden artwork. Sucrose (cane sugar, beet sugar, chemically $\alpha$-D-glucopyranosyl- $\beta$-D-fructofuranoside, $\mathrm{C}_{12} \mathrm{H}_{22} \mathrm{O}_{11}$ ), is easily dissolved in water, non-toxic and does not corrode metals. Its chemical structure is similar to cellulose, it has a low molecule weight and it penetrates wood easily and quickly. It has a crystalline structure suitable for wood reinforcement. It dissolves in water at a normal temperature so it does not have to be heated for impregnation. It has a chemical affinity to cellulose and diffuses in wood easily. A raster electron microscopic study found that sucrose penetrates cell walls where it crystallizes. This corresponds to its excellent stabilization of wood dimensions. Modified wood retains its natural appearance; and the price of sucrose is low compared to other substances (Morgós and Imazu 1993).

\footnotetext{
${ }^{1}$ Mendel University in Brno, Faculty of Forestry and Wood Technology, Department of Wood Science, Zemědělská 3, Brno, 61300, Czech Republic 
Other research (Stamm 1955) compared impregnation by sucrose and impregnation by invert sugar with the aim to decrease water vapour absorption and water absorption. The invert sugar (obtained by acid or enzymatic sucrose hydrolysis) was found to decrease water absorption better than crystalline sucrose. Both ways achieved better results than unmodified specimens. However, the invert sugar does not increase the hardness of wood comparing to sucrose, which improves this property.

Another experiment published by Lesar et al. (2009) compared water vapour absorption in specimens impregnated by compounds of boron, sodium chloride and glucose. Impregnation by sodium chloride had a larger effect on the equilibrium moisture content (EMC) than impregnation by boron compounds. An increasing concentration of $\mathrm{NaCl}$ in wood was found to be accompanied by increase in EMC. Boric acid, borax, sodium chloride and glucose have all crystalline structures. The researchers assume that these substances are bound in wood mechanically (not chemically) and thus they do not cause any structural changes to wood. The substances are deposited in the form of smaller or larger crystals in cell walls and cell lumens. The crystals dissolve in an extremely humid environment and crystallize again when air humidity decreases. The absorbed and free water in wood works as a dissolvent. This process of crystallization and dissolution is reversible.

The difference between sodium chloride and sucrose is their water solubility - it is six times higher for sucrose than for $\mathrm{NaCl}$. Thus we can assume smaller weight percentage gain (WPG) within $\mathrm{NaCl}$ impregnation. $\mathrm{An}$ important factor in the case of $\mathrm{NaCl}$ will be its hygroscopicity.

Modification of wood with sucrose is commonly used in the preservation of archaeological wood artifacts (Morgós and Imazu 1993).

The use of these materials should be for interior due to increased hygroscopic properties of modified materials. Another alternative would be used for outdoor in small concentrations of sucrose when there is not such a large increase in EMC and adding some biocide compounds.

The main aim of this study was to provide better dimensional stability of the wood of poplar. The authors chose substances that are water soluble and come from natural sources and could replace e.g. synthetic resins. Changes in properties of solid wood in dependence on conditions of use can be huge and need to be eliminated as much as possible (Dejmal et al. 2009).

\section{MATERIALS AND METHODS}

\section{Samples}

Specimens of white poplar (Populus alba $\mathrm{L}$.) with dimensions $30 \times 20 \times 20 \mathrm{~mm}(\mathrm{~L} \times \mathrm{T} \times \mathrm{R})$ were oven dried in a laboratory drying chamber at a temperature of $103 \pm 2{ }^{\circ} \mathrm{C}$ until constant mass was achieved. Then the specimens were weighed and dimensions were measured.

\section{Vacuum-pressure impregnation}

The impregnation solution contained water (dissolvent) and the impregnation substance, either sodium chloride or sucrose. Due to the lower water solubility of $\mathrm{NaCl}$ in comparison to sucrose, the impregnation solutions with $\mathrm{NaCl}$ were about 6 times less concentrated. In total, five different concentrations of water dilutions were prepared for each substance (Table 1). The mixture was mixed properly in a plastic container and then left standing for 24 hours at a temperature of $20^{\circ} \mathrm{C}$. After 24 hours all $\mathrm{NaCl}$ and sucrose were dissolved and homogeneous dilutions were gained. 
Table 1. Groups of samples and concentrations of substance in the solution.

\begin{tabular}{cll}
\hline Group & Concentration $(\mathrm{NaCl})$ & Concentration (sucrose) \\
& & \\
\hline $\mathrm{I}$ & $1 \mathrm{~g} / 100 \mathrm{ml} \mathrm{H} \mathrm{H}_{2} \mathrm{O}$ & $6,25 \mathrm{~g} / 100 \mathrm{ml} \mathrm{H} \mathrm{O}_{2} \mathrm{O}$ \\
$\mathrm{II}$ & $2 \mathrm{~g} / 100 \mathrm{ml} \mathrm{H} \mathrm{H}_{2} \mathrm{O}$ & $12,5 \mathrm{~g} / 100 \mathrm{ml} \mathrm{H} \mathrm{O}_{2} \mathrm{O}$ \\
$\mathrm{III}$ & $4 \mathrm{~g} / 100 \mathrm{ml} \mathrm{H} \mathrm{H}_{2} \mathrm{O}$ & $25 \mathrm{~g} / 100 \mathrm{ml} \mathrm{H} \mathrm{O}_{2} \mathrm{O}$ \\
$\mathrm{IV}$ & $8 \mathrm{~g} / 100 \mathrm{ml} \mathrm{H} \mathrm{H}_{2} \mathrm{O}$ & $50 \mathrm{~g} / 100 \mathrm{ml} \mathrm{H} \mathrm{O}_{2} \mathrm{O}$ \\
V & $16 \mathrm{~g} / 100 \mathrm{ml} \mathrm{H}_{2} \mathrm{O}$ & $100 \mathrm{~g} / 100 \mathrm{ml} \mathrm{H}_{2} \mathrm{O}$ \\
& unmod. (reference) & unmod. (reference) \\
VI & specimens & specimens \\
\hline
\end{tabular}

The impregnation was conducted using the vacuum-pressure device JHP 1-072. Specimens from groups $\mathrm{I}-\mathrm{V}$ were impregnated. For all groups a specific process of impregnation was chosen, based on vacuum phase only, without overpressure. The vacuum based impregnation was carried out in three steps. The pressure was decreased to $20 \mathrm{kPa}$ of absolute pressure in each step and then maintained for chosen time. Breaks at atmospheric pressure followed after each vacuuming step and the impregnation solution was filled up (Table 2).

Table 2. Pressures and times used for phases of vacuum-pressure impregnation.

\begin{tabular}{llll}
\hline Phase & $\begin{array}{l}\text { Time t } \\
(\text { min. })\end{array}$ & $\begin{array}{l}\text { Absolute } \\
\text { pressure }(\mathrm{kPa})\end{array}$ & Phase description \\
\hline 1 & $15 / 60$ & $50 / 20$ & slight pressure decrease \\
\hline relaxation & 10 & $101,3 \pm 1$ & $\begin{array}{l}\text { filling up the } \\
\text { impregnation solution }\end{array}$ \\
\hline 2 & 80 & 20 & \\
relaxation & 10 & $101,3 \pm 1$ & $\begin{array}{l}\text { filling up the } \\
\text { impregnation solution }\end{array}$ \\
\hline 3 & 60 & 20 & $\begin{array}{l}\text { removal of the } \\
\text { impregnation solution }\end{array}$ \\
\hline
\end{tabular}

\section{Testing of physical properties}

The specimens were oven dried again after impregnation until the constant mass. Then they were weighed and dimensions were measured again. The weight percentage gain (1), longitudinal swelling due to modification (2) and surface swelling due to modification (3) was calculated as follows:

$$
W P G=\frac{m_{m}-m_{n}}{m_{n}} \cdot 100
$$

Where: WPG is the weight percentage gain (\%), $\mathrm{m}_{\mathrm{m}}$ is the mass of an oven dried modified specimen $(\mathrm{g})$ and $\mathrm{m}_{\mathrm{n}}$ is the mass of an unmodified oven dried specimen $(\mathrm{g})$.

$$
\alpha_{L}=\frac{l_{m}-l_{n}}{l_{n}} \cdot 100
$$

Where: $\alpha_{\mathrm{L}}$ is the longitudinal swelling due to modification $(\%), 1_{\mathrm{m}}$ is the length of an oven dried modified specimen $(\mathrm{mm})$ and $1_{\mathrm{n}}$ is the length of an oven dried unmodified specimen $(\mathrm{mm})$. 


$$
\alpha_{S}=\frac{S_{m}-S_{n}}{S_{n}} \cdot 100
$$

Where: $\alpha_{\mathrm{S}}$ is the surface swelling due to modification (\%), $\mathrm{s}_{\mathrm{m}}$ is the surface dimension of an oven dried modified specimen $\left(\mathrm{mm}^{2}\right)$ and $\mathrm{s}_{\mathrm{n}}$ is the surface dimension of an oven dried unmodified specimen $\left(\mathrm{mm}^{2}\right)$.

The specimens were conditioned in the laboratory (at temperature of $20{ }^{\circ} \mathrm{C}$ and a relative air humidity of $20 \%$ ) for 60 days until they reached equilibrium moisture content of $4,1 \%$.

The moisture absorption test was done by placing the specimens into the desiccator above the water level. The lid of the desiccator was hermetically sealed and the specimens were left inside for another 60 days. This time ensures that the equilibrium moisture content of wood was reached. We also checked that the mass of the specimens remained constant after this time. The environment inside the hermetically sealed desiccator became saturated with water vapours (the relative air humidity reached nearly $100 \%$ ). The conditioning process was conducted at a temperature of $20^{\circ} \mathrm{C}$. Xylene was used to prevent mildew in the desiccator. The measured values were used to calculate the anti-swelling efficiency (4) and moisture exclusion efficiency (5):

$$
A S E=\frac{S_{n}-S_{m}}{S_{n}} \cdot 100
$$

Where: ASE is anti-swelling efficiency (\%), $\mathrm{S}_{\mathrm{n}}$ is volume swelling of an unmodified specimen (\%) and $\mathrm{S}_{\mathrm{m}}$ is volume swelling of a modified specimen (\%).

$$
M E E=\frac{E M C_{n}-E M C_{m}}{E M C_{n}} \cdot 100
$$

Where: MEE is moisture exclusion efficiency (\%), $\mathrm{EMC}_{\mathrm{n}}$ is equilibrium moisture content of an unmodified specimen (\%) and $\mathrm{EMC}_{\mathrm{m}}$ is equilibrium moisture content of a modified specimen (\%).

\section{Statistical methods}

The data were processed in software STATISTICA 9.0. Extreme values were removed using a box-graph (box plot). It was also necessary to investigate the distribution of the data type using a normal probability graph. Shapiro-Wilks test verified the data normality. This information is obtained for further processing. Afterwards the important moment and quantile characteristics (median, arithmetic average, standard deviation, etc.) were calculated. Then we can perform statistical tests (ANOVA, linear regression, etc.), which can reject the null hypothesis or not. 


\section{RESULTS AND DISCUSSION}

\section{Treatments}

One of the most important factors affecting the changes in wood properties is weight percentage gain (WPG). A close relationship between the concentration of the impregnation solution (content of the substance in water) and the reached values of WPG has been proved. The values of WPG fluctuated between 8 and $75 \%$ after the modification by sucrose and between 0,6 and $30 \%$ after modification by $\mathrm{NaCl}$ (Figure 1). The values of WPG achieved with sucrose are higher, which correlates to the higher concentrations of sucrose in water dilutions compared to dilutions concentrations of $\mathrm{NaCl}$. In spite of this, $\mathrm{NaCl}$ and sucrose penetrate wood very well and can crystallize in the wood after drying. According to Morgós (2003) sucrose penetrates cell walls easily and creates hydrogen bonds with cellulose molecules. On the other hand, Lesar (2009) assumes that $\mathrm{NaCl}$ is bound in wood only mechanically (not chemically) so no structural change of wood occurs. In the table 3 you can see also average retention of $\mathrm{NaCl}$ and sucrose.

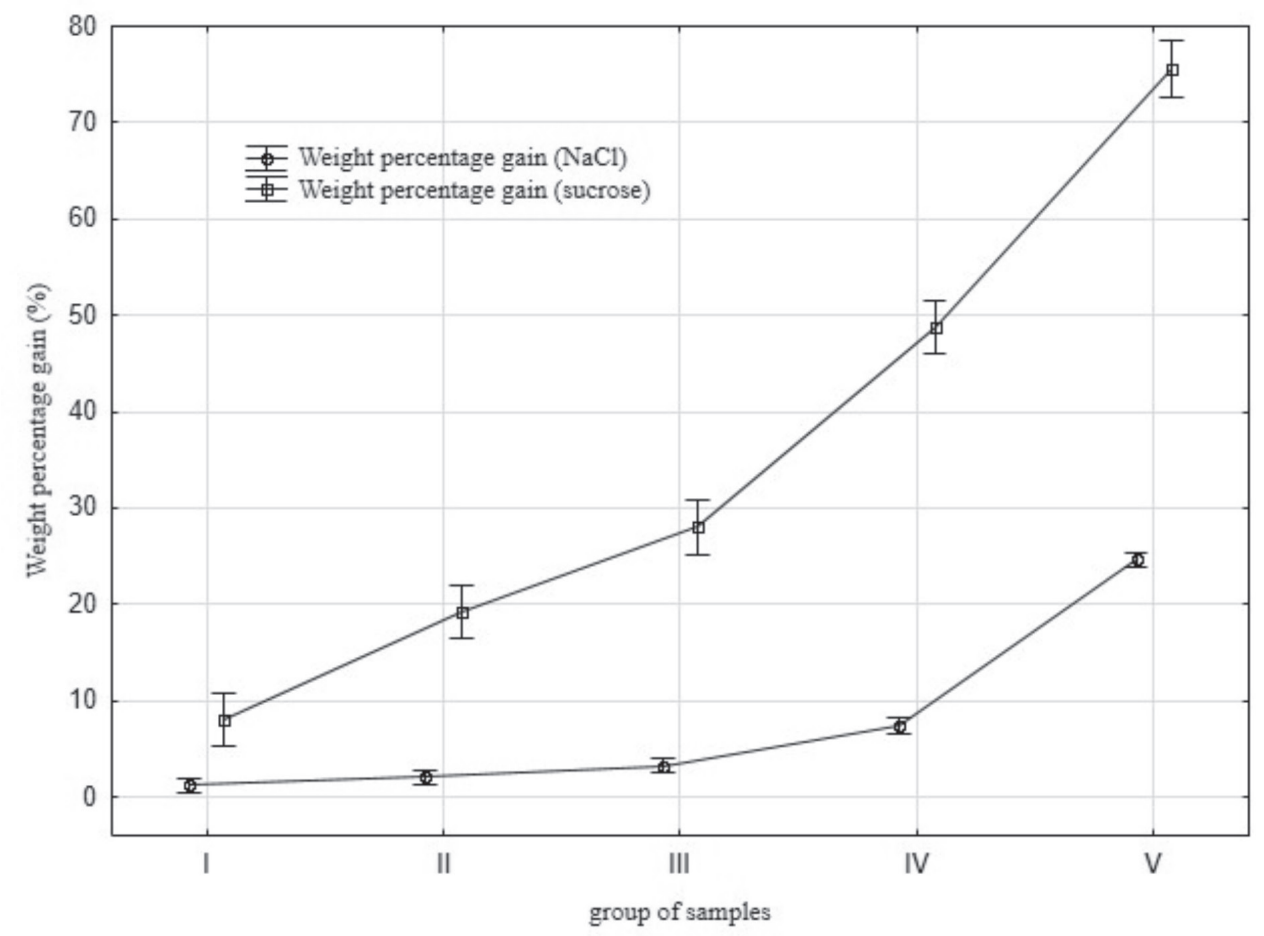

Figure 1. Anova - Weight percentage gain dependence on the concentration of the impregnation solution by group. 
Table 3. Average retention of $\mathrm{NaCl}$ and sucrose.

\begin{tabular}{cc}
\hline Group & $\begin{array}{c}\text { Retention } \\
\left(\mathrm{kg} \cdot \mathrm{m}^{-3}\right)\end{array}$ \\
\hline $\mathrm{NaCl} \mathrm{I}$ & 4,7 \\
$\mathrm{NaCl} \mathrm{II}$ & 8 \\
$\mathrm{NaCl}$ III & 14 \\
$\mathrm{NaCl} \mathrm{IV}$ & 27 \\
$\mathrm{NaCl} \mathrm{V}$ & 72 \\
Sucrose I & 31 \\
Sucrose II & 63 \\
Sucrose III & 100 \\
Sucrose IV & 160 \\
Sucrose V & 258 \\
\hline
\end{tabular}

Požgaj et al. (1997) states the density $\rho_{0}$ of poplar wood to be $390 \mathrm{~kg} \mathrm{~m}^{-3}$. The mean density $\left(\rho_{0}\right)$ of reference (non-impregnated) specimens was $390 \mathrm{~kg} \cdot \mathrm{m}-3$. In dependence on the WPG the density of the specimens of Populus alba grew up to $676 \mathrm{~kg} \mathrm{~m}^{-3}$ in the sucrose impregnated specimens and up to $510 \mathrm{~kg}$ $\mathrm{m}^{-3}$ in the $\mathrm{NaCl}$ impregnated specimens.

The differences in density of specimens before and after modification (Figure 2) showed that the $\mathrm{NaCl}$ impregnation in group I $(1 \mathrm{~g} / 100 \mathrm{ml})$ caused a slight decrease in the density, which can be explained by larger swelling of wood and the slight increase in weight after modification with a very small concentration of $\mathrm{NaCl}$ in the impregnation solution. Starting from group II the density increased based on the concentration of $\mathrm{NaCl}$ in the impregnation solution. Group $\mathrm{V}$ reached an average density increase of $63 \mathrm{kgn} \mathrm{m}^{-3}$, which means increase of $17 \%$ compared to density before modification. Regarding sucrose impregnation (Figure $2)$, the density of the group I increased as well $(6,25 \mathrm{~g} / 100 \mathrm{ml})$. Group V reached an average density increase of $244 \mathrm{~kg} \mathrm{~m}^{-3}$, which means increase of $64 \%$ compared to density before modification. 


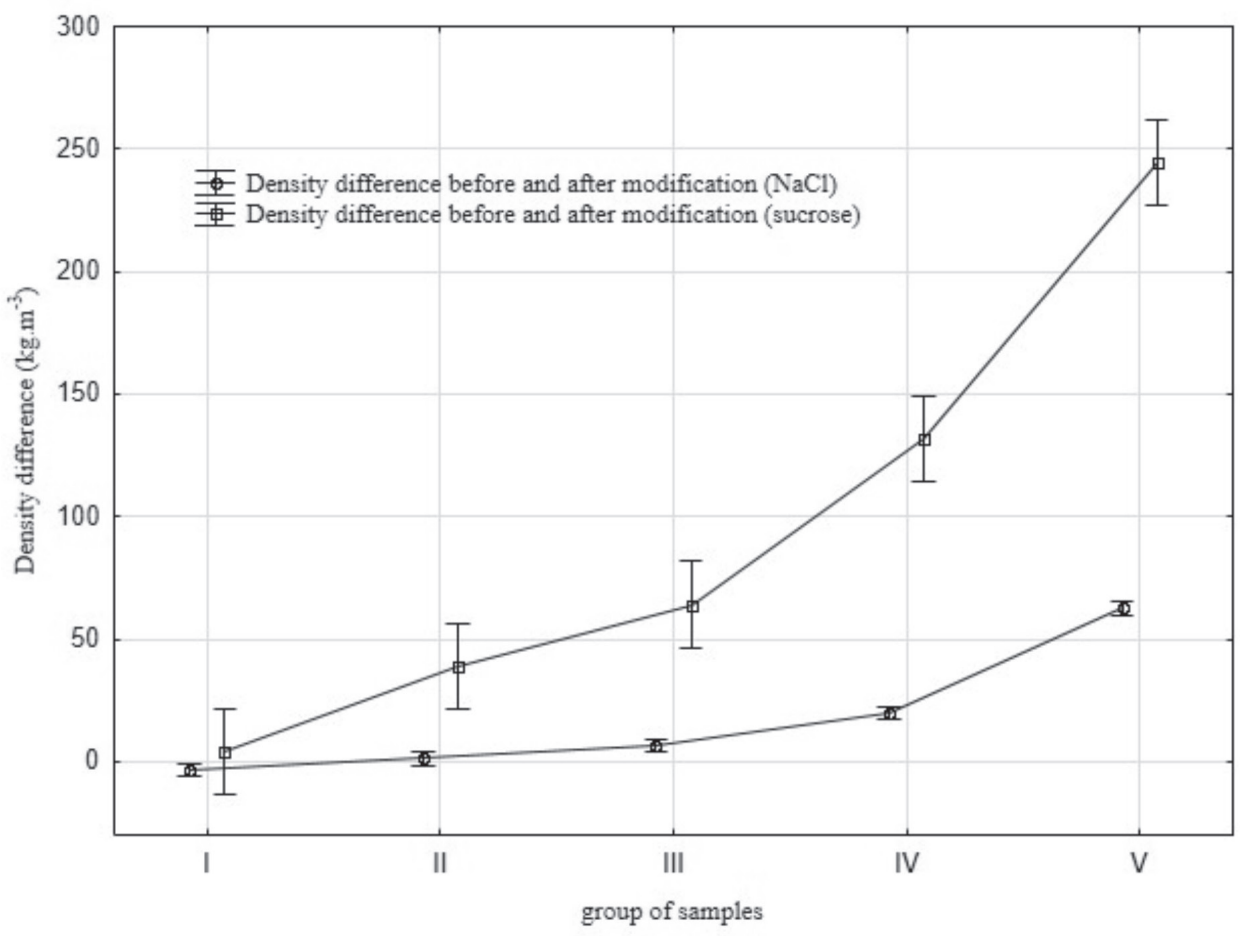

Figure 2. Anova - dependence of density differences before and after modification on the concentration of the impregnation solution by group.

Another indicator was swelling caused by the wood modification. Longitudinal swelling $\left(\alpha_{L}\right)$ due to modification follows the same rules as swelling due to moisture absorption. The average values in the longitudinal direction of group $\mathrm{V}$ are $0,6 \%(\mathrm{NaCl})$ and $1,65 \%$ (sucrose). The average values of swelling $(\alpha s)$ in the transverse directions due to modification did not differ much in groups I-IV - they ranged around $1,8 \%(\mathrm{NaCl})$ and 3,6 \% (sucrose). Group V (sucrose) also exhibited similar average values. Group V $(\mathrm{NaCl})$ exhibited almost three times higher values - the average value of swelling was 5,2 \%. The swelling of samples due to modification confirms the hypothesis that the wood expanded by the $\mathrm{NaCl}$ and the sucrose crystallization. This is consistent with that $\mathrm{NaCl}$ and sucrose were able to penetrate into cell walls, where they crystallized after drying. Further, we confirmed the influence of swelling due to modification on weight gain using linear regression model (Figure 3 and 4). The dependence of swelling due to modification on WPG is higher for $\mathrm{NaCl}$ impregnation than for sucrose impregnation. 


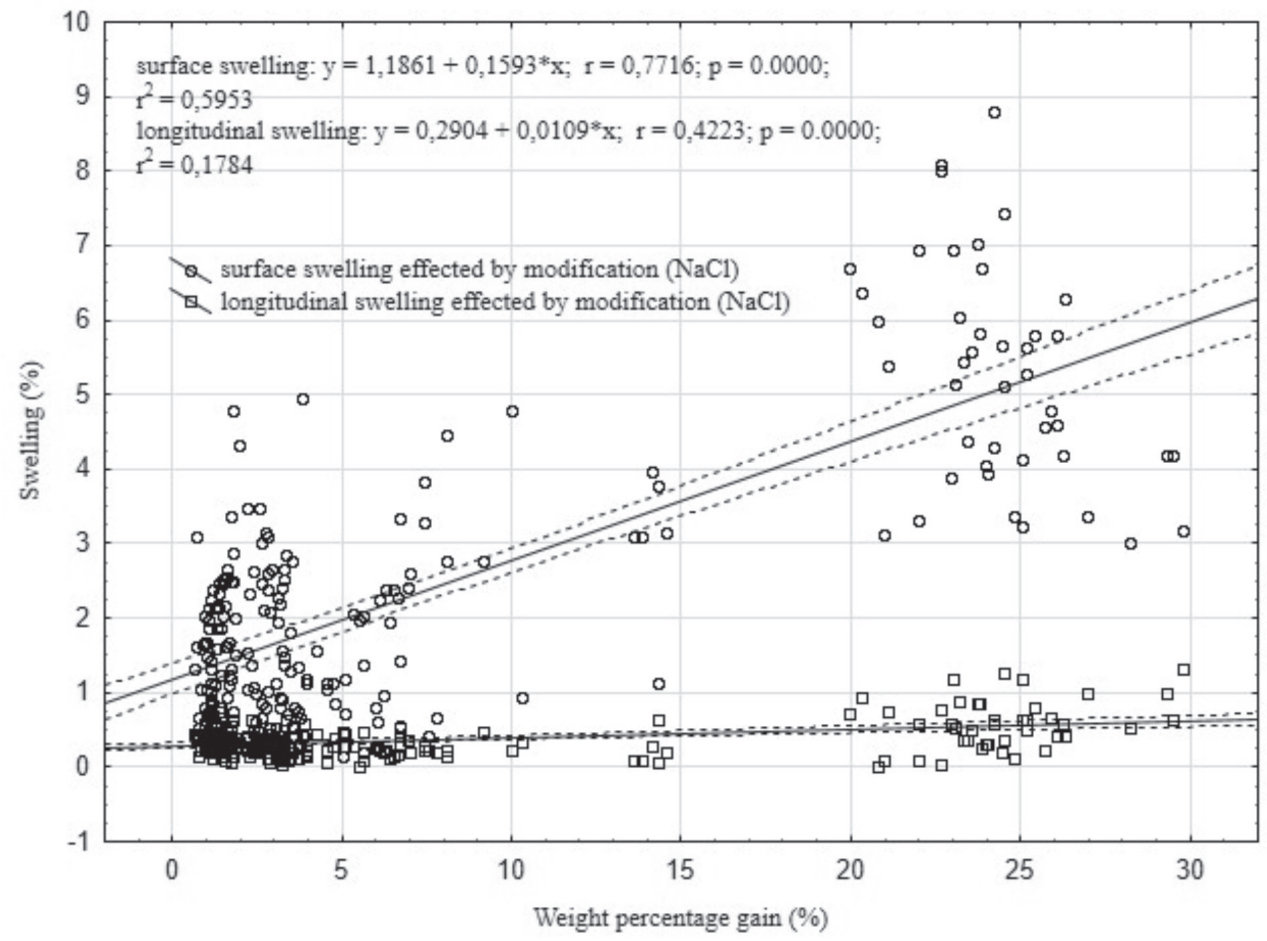

Figure 3. Model of linear regression - dependence of swelling due to modification on weight percentage gain $(\mathrm{NaCl})$.

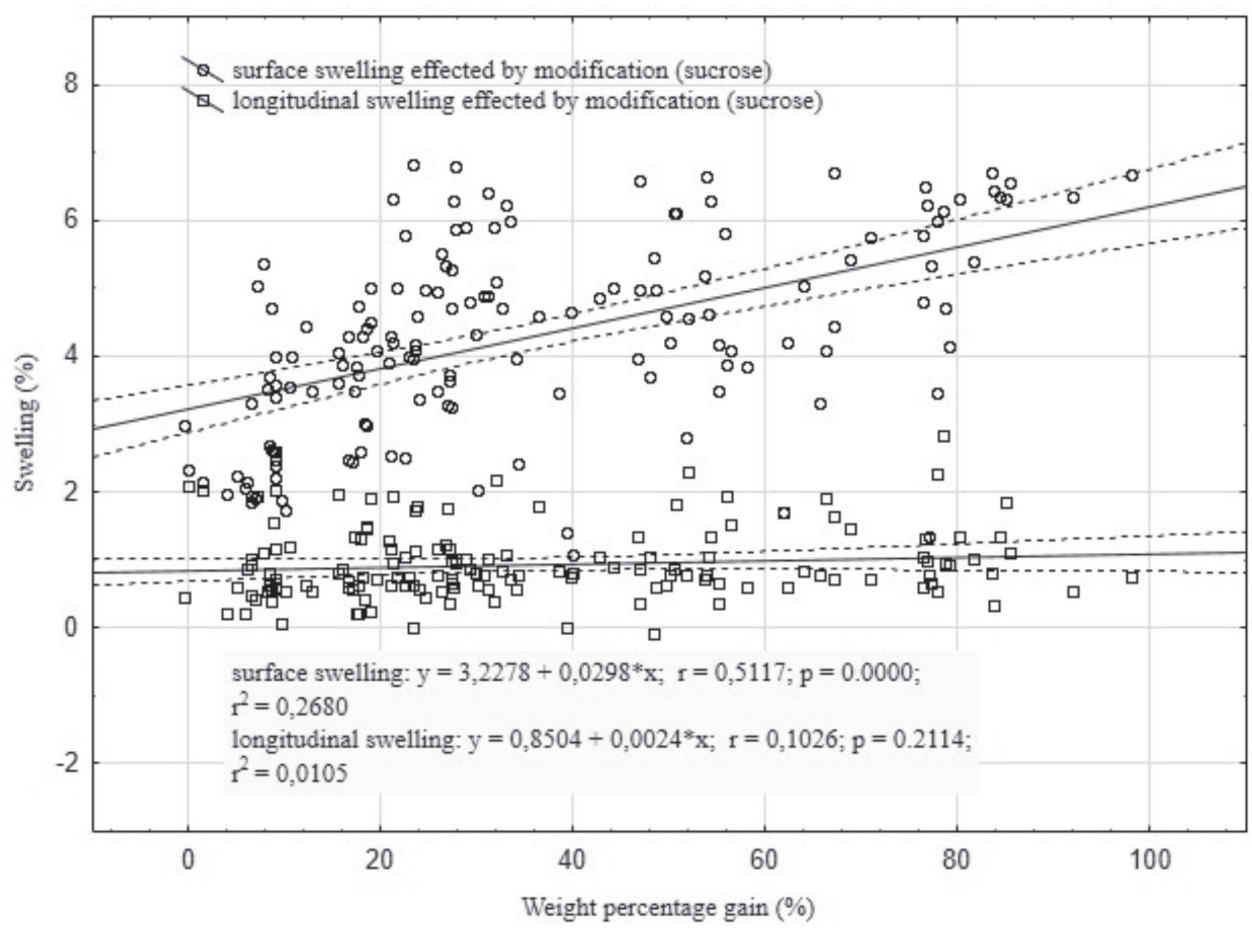

Figure 4. Model of linear regression - dependence of swelling due to modification on weight percentage gain (sucrose). 


\section{Moisture absorption experiments}

Swelling due to moisture absorption is the main investigated property of this research. In this case, the average values of volume swelling $\left(\mathrm{S}_{\mathrm{n}}\right)$ were the highest in the reference group: 12,7\% (Figure 5). Groups I ( $\mathrm{NaCl}$ ) and I (sucrose) exhibited average values of volume swelling $\left(\mathrm{S}_{\mathrm{m}}\right)$ of $11,4 \%$ and $8,1 \%$, respectively. Volume swelling in groups $\mathrm{V}(\mathrm{NaCl})$ and $\mathrm{V}$ (sucrose) was $9,6 \%$ and $7,7 \%$, respectively. We found statistically significant differences when these groups (I and V) were compared with the reference group (VI). Impregnation by $\mathrm{NaCl}$ and sucrose manifested a positive effect on the dimensional stability of wood; the effect was higher in sucrose. It is probably caused by the preceding wood swelling caused by modification $(\mathrm{NaCl}$ and sucrose crystals in the cell wall) - moisture absorption does not increase the dimensions as much as it would in unmodified wood. The dimensional stability increases due to modification by these substances. Group I and V (sucrose) showed the best indicator ASE, $36 \%$ (group I) and $39 \%$ (group V). Group V showed the best result of ASE in case of $\mathrm{NaCl}(24 \%)$.

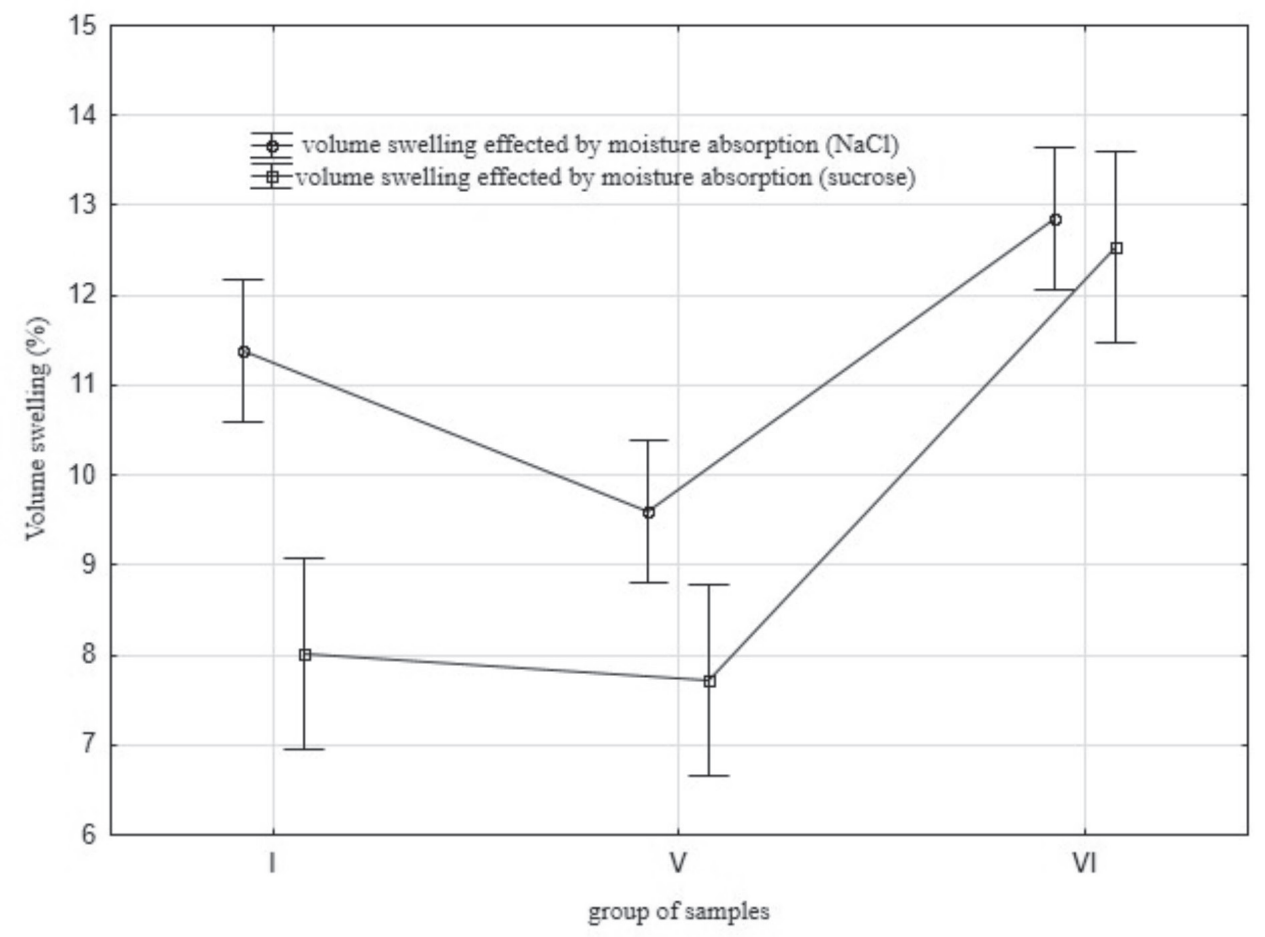

Figure 5. Anova - dependence of volume swelling due to moisture absorption on the concentration of the impregnation solution by group. 
Another examined parameter was the average equilibrium moisture content $\left(\mathrm{EMC}_{\mathrm{n}}\right)$ was about $30 \%$ in the reference group (Figure 6). According to Siau (1995) the fibre saturation point is about $30 \%$; this means the maximum saturation of cell walls was achieved (wood contained the maximum amount of bound water). Group $\mathrm{I}(\mathrm{NaCl})$ reached an average $\mathrm{EMC}_{\mathrm{m}}$ of $31,4 \%$, but no statistically significant differences were proved when compared with the reference group. On the other hand, in group I (sucrose) the average $\mathrm{EMC}_{\mathrm{m}}$ was $35,7 \%$ and statistically significant differences were found. The EMC in group $\mathrm{V}(\mathrm{NaCl})$ increased considerably - the average value was $66 \%$. The $\mathrm{EMC}_{\mathrm{m}}$ in group $\mathrm{V}$ (sucrose) increased to $45 \%$. The $\mathrm{EMC}_{\mathrm{m}}$ increases with an increasing $\mathrm{NaCl}$ concentration in the impregnation solution, as has also been confirmed by Lesar et al. (2009). These values in group $\mathrm{V}(\mathrm{NaCl})$ were achieved with an average WPG of about 22 $\%$, while the value of EMC within sucrose impregnation was only $45 \%$ with WPG of $70 \%$, which is three times more than in $\mathrm{NaCl}$ impregnation. With a relatively low content of $\mathrm{NaCl}$ in wood its hygroscopicity is considerably increased in contrast to sucrose impregnation. The model of linear regression (Figure 7 and 8) shows that there is a statistically significant dependence between $\mathrm{EMC}_{\mathrm{m}}$ and WPG: the higher WPG, the higher $\mathrm{EMC}_{\mathrm{m}}$. This means that the more $\mathrm{NaCl}$ and sucrose there is in wood, the more the wood will absorb moisture, which affects the resulting $\mathrm{EMC}_{\mathrm{m}}$. The MEE (moisture exclusion efficiency) indicator gained negative values. The average value of group I $(\mathrm{NaCl})$ was $4.6 \%$, group $\mathrm{V}(\mathrm{NaCl})-120 \%$, group I (sucrose) - $33 \%$ and group V (sucrose) - $61 \%$. According to Morgós (2003), natural sucrose is highly hygroscopic at relative air humidity $\varphi>85 \%$. At lower ambient humidity sucrose manifests the opposite - it decreases wood hygroscopicity.

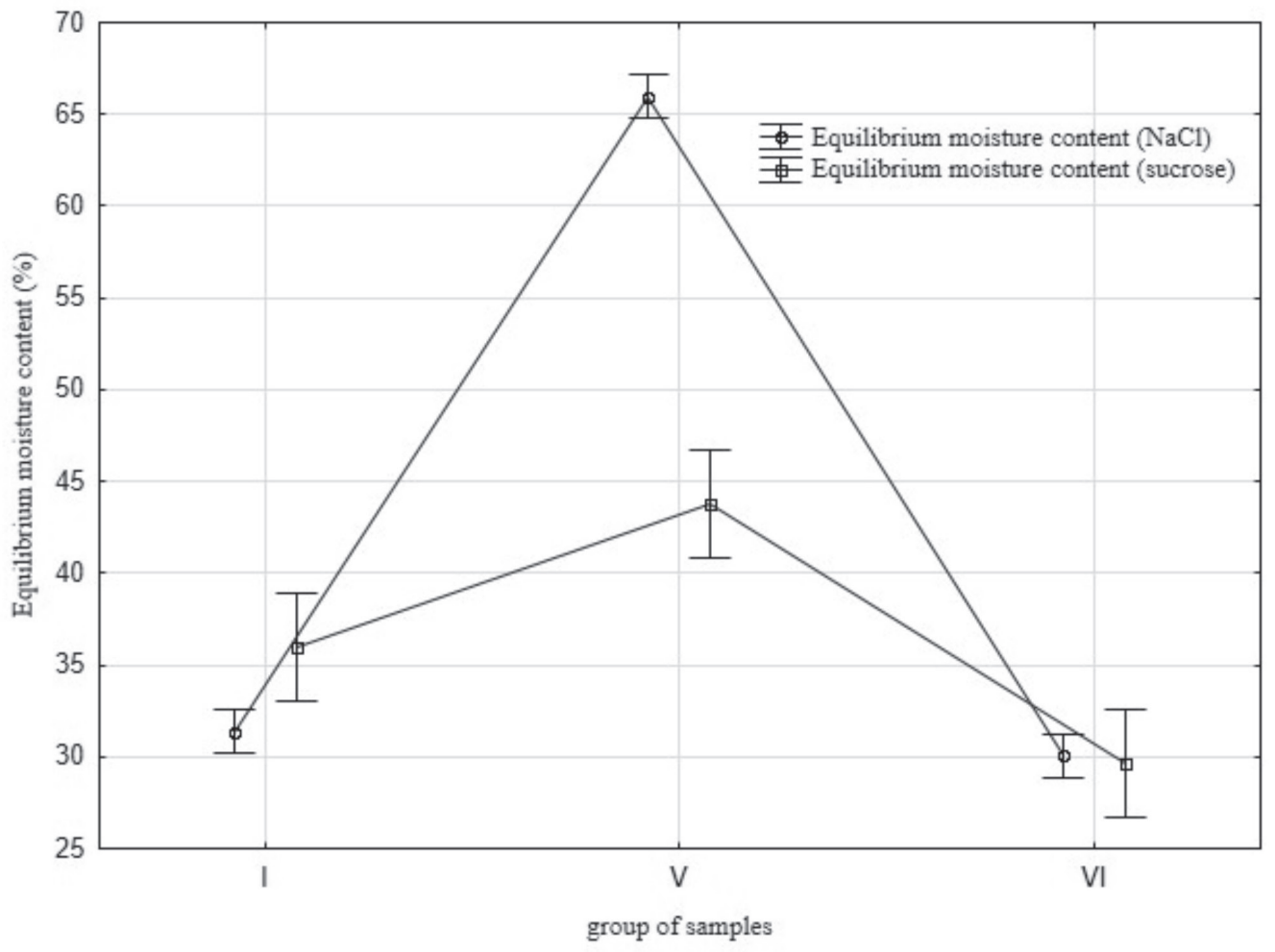

Figure 6. Anova - Equilibrium moisture content dependence on the concentration of the impregnation solution by group. 


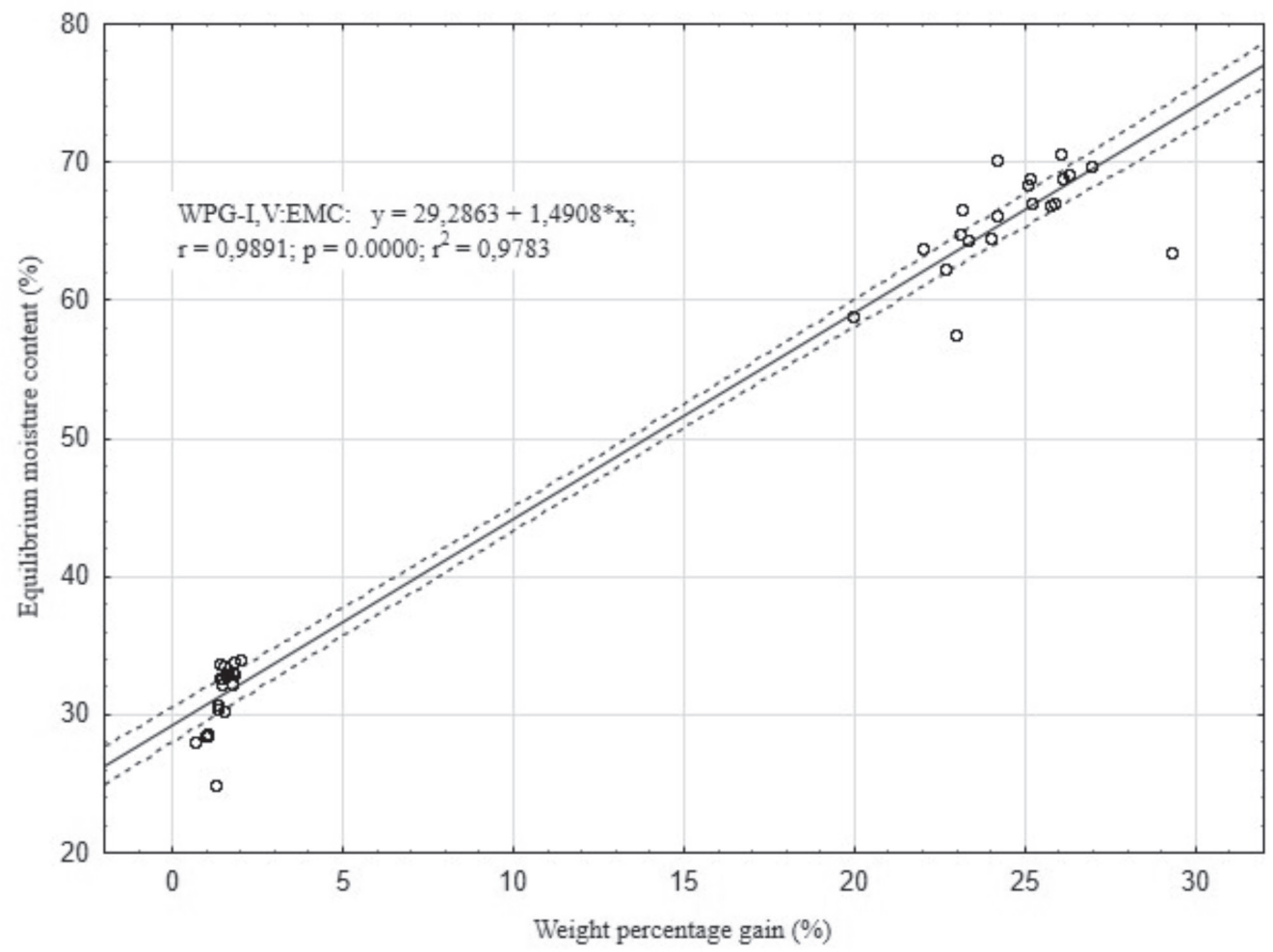

Figure 7. Model of linear regression - Equilibrium moisture content dependence on weight percentage gain $(\mathrm{NaCl})$.

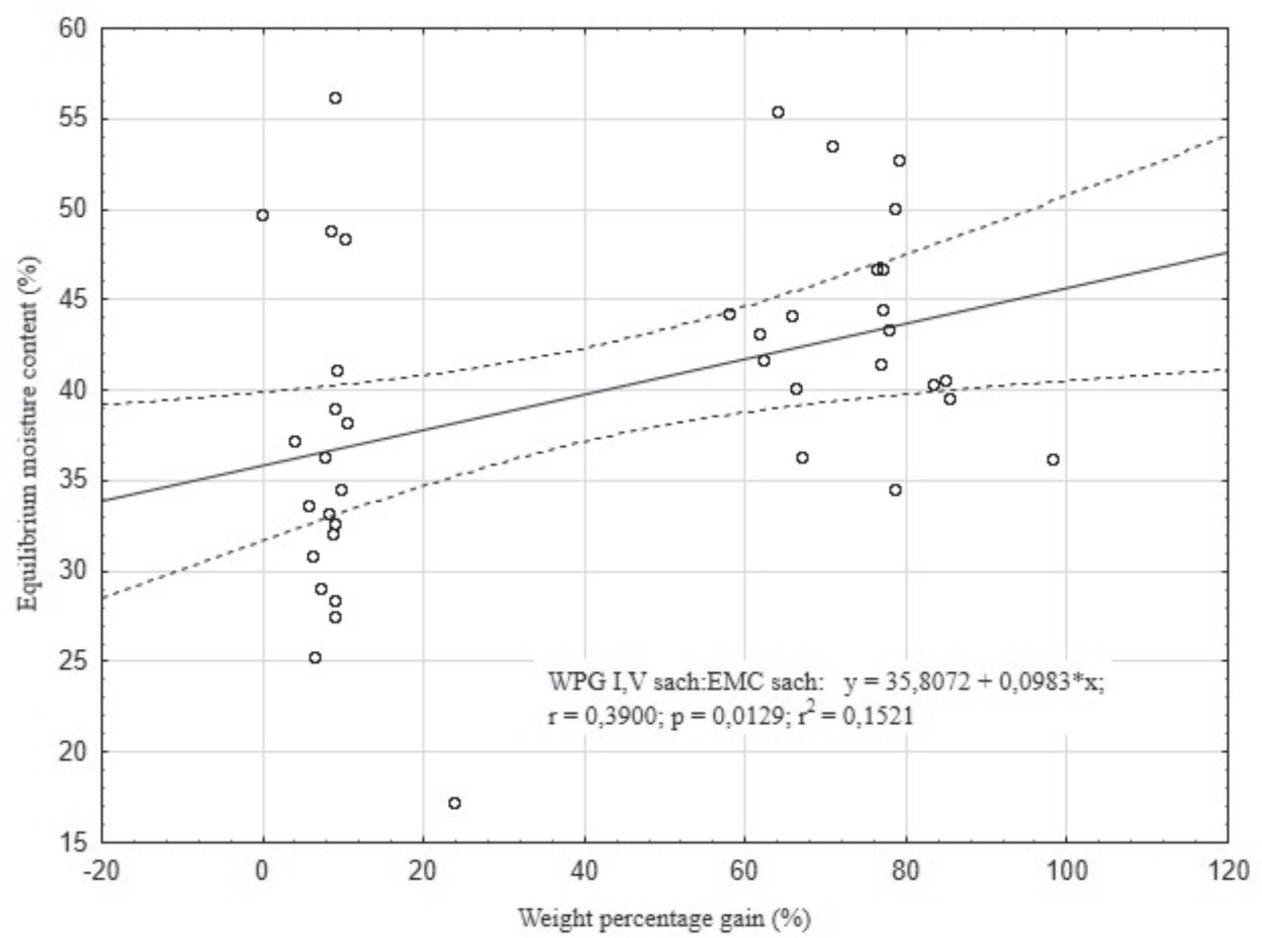

Figure 8. Model of linear regression - Equilibrium moisture content dependence on weight percentage gain (sucrose). 
Group $\mathrm{V}(\mathrm{NaCl})$ exhibited enhanced properties of ASE but with the rapid increase in EMC, which is negative effect. Group I and V (sucrose) showed the best improvement of dimensional stability but group $\mathrm{V}$ provided little additional benefit while greatly increasing $\mathrm{EMC}_{\mathrm{m}}$. Higher EMC could cause increases susceptibility to mold and wood-decaying fungi. Impregnation with the lowest concentration of sucrose (group I) offers the best combination of reduction in swelling and relatively small increases in EMC and WPG.

\section{CONCLUSION}

Sucrose and $\mathrm{NaCl}$ impregnation are environment-friendly methods for wood modification using natural degradable substances. Poplar wood has a homogeneous structure and is fast-growing; its sapwood can be easily impregnated. The experimental measuring proves that crystallized sucrose and $\mathrm{NaCl}$ contained within wood can considerably affect its physical properties. The WPG increases with an increasing concentration of $\mathrm{NaCl}$ and sucrose in the impregnation solution and influences other wood properties. Tests also confirmed wood swelling due to modification. This evidences that $\mathrm{NaCl}$ and sucrose reached the cell walls where they crystallized after drying. Due to this wood swelled and its weight increased. Density increased in dependence on the concentration of the solution. Moisture absorption tests confirmed a high hygroscopicity of modified samples; the highest hygroscopicity was found in the highest concentration of $\mathrm{NaCl}$. EMC of $\mathrm{NaCl}$ impregnation increased by $120 \%$ on average in comparison with the reference group. Swelling caused by moisture absorption was lower in modified groups than in the reference groups, for both of the used substances. Modification reduced volume swelling caused by moisture absorption and thus we can state that it has a positive effect on the dimensional stability of wood. This is caused by wood swelling brought about by the modification itself. The lowest concentration of sucrose showed the best results from the perspective of improved dimensional stability and small increases in equilibrium moisture content.

Usage of the modified materials outdoors or in conditions of increased humidity cannot be recommended except small concentrations of sucrose when there is not such a large increase in EMC and adding some biocide compounds. Although there is still problem with potential leaching from wood. They are more suitable for interiors, e.g. for furniture, panelling and floors. Further research could ascertain how the modified wood would behave in lower relative air humidity. For this EMC in different ambient conditions could be ascertained, concentrations of $\mathrm{NaCl}$ and sucrose in the impregnation mixture could be increased and impregnation could be explored in combination of vacuum pressure and overpressure. It is also possible to combine impregnation with other ways of modification (e.g. thermal). Another topic for research could be the examination into the resistance to wood-destroying fungi and insects. Also an exploration should be conducted into fasteners regarding their potential corrosion.

\section{ACKNOWLEDGEMENTS}

The paper was created within the research plan of the Faculty of Forestry and Wood Technology, Mendel University in Brno, MSM 6215648902 Forest and Wood - Support for Functionally Integrated Forest Management and Use of Timber as Renewable Material. 


\section{REFERENCES}

Baar, J.; Gryc, V. 2012. The analysis of tropical wood discoloration caused by simulated sunlight. European journal of wood and wood products 70(1): 263-269.

Dejmal, A.; Šrajer, J.; Hrázský, J. 2009. Determination of density profiles of unevenly compressed wood of Populus tremula using the X - RAY DENSE - LAB laboratory device. Acta univ. agric. Et silvic. Mendel. Brun., LVII, No. 5, pp 71-78. ISSN 1211-8516.

Gryc, V.; Vavrčík, H.; Horáček, P. 2007. Variability in swelling of spruce (Picea abies /L./ Karst.) wood with the presence of compression wood. Journal of forest science 53: 243-252.

Hill, C.A.S. 2006. Wood Modification: Chemical, Thermal and Other Processes. University of Wales, Bangor. John Wiley \& Sons, Ltd, Chichester.

Lesar, B.; Gorišek, Ž.; Humar, M. 2009. Sorption Properties of Wood Impregnated with Boron Compounds, Sodium Chloride and Glucose. Drying Technology 27(1):94-102.

Morgós, A.; Imazu, S. 1993. Comparing conservationmethods for waterlogged wood using sucrose, mannitol and their mixture. In: Hoffmann, P. (ed). Proceedings of the $5^{\text {th }}$ ICOM Group on Wet Organic Archaeological Materials Conference. Portland: ICOM, pp.287-308.

Požgaj, A.; Chovanec, D.; Kurjatko, S.; Babiak, M. 1997. Štruktůra a vlastnosti dreva. Bratislava.

Siau, F.J. 1995. Wood: Influence of moisture content on physical properties. Virginia Polytechnic Institute and State University.

Stamm, A.J. 1955. Minimizing wood shrinkage and swelling - Treatment with sucrose and invert sugar. Madison, Wisconsin, USA.

Vigué, J. 2006. Wood. Rebo Productions Czech republic. 
